\title{
FROM INSTRUCTION TO CONSTRUCTION: A PEDAGOGY FOR EFFECTIVE LEARNING OF SCIENCE
}

\author{
Francis Peter S.J.*
}

Imagine three professionals namely, a computer engineer, a medical lab technician and a college teacher have been recalled to join duty 20 years after they had quit their jobs. You would agree with me that the first two - the engineer and the technician, would be reluctant to accept the invitation citing the tremendous changes in their respective fields. Their professions would have progressed significantly, instruments would all be sophisticated and new; and many of the procedures now in practice would be unfamiliar to the incumbents. I am equally sure that the poor teacher alone would not hesitate to accept the invitation. She would be almost sure to find the same classroom, nearly the same curriculum, the same texts and the same methodology! Even if there were marginal changes they would offer her little problem. After 20 years gap this teacher would take to teaching as duck to water!

This little imaginary story is just to highlight the rate and route of transformation that characterise the present times, appropriately called the knowledge era. Change, we often hear said, is the only thing that is permanent! In this fast paced world, where there have been more changes in the last couple of decades, than perhaps in the last hundred years, the great and respected enterprise called science education has exhibited little or no change! Our profession, which ought to have been in the vanguard of progress, has somehow been slow and reluctant to accept and implement changes.

* Loyola College, Chennai. 
I am happy that Christ College has taken this initiative to make us pull up our socks, address the issues of reviving and revitalizing interest in learning science. Permit me to pitch in my bit before this enthusiastic and committed group of teacherlearners, some insights and interests I have been mulling over recently. If there was anyone who could break free from the shackles of dead habits and break new path it is you. And the time is now. We owe it to the country we all dream of transforming into a powerful unified and well endowed nation. I hope just to give you a whiff of the fragrance of an alternate approach to teaching/learning and create in you an appetite to explore, adapt, adopt and become adept in them.

\section{Assumptions Underlying the Current Model of Teaching - A Critique}

We need to begin by exploring our concept of knowledge. The teaching fraternity views knowledge as a product; symbolized and packaged in solid forms such as books, notes, videos, floppies or CDs. It is area specific, prefabricated and gift wrapped and comes in required density to suit the clientele each teacher caters to. Our concern as educators is to get this knowledge into the heads of our students. An efficient teacher is one who can transmit the contents of this package to as many learners as possible, in as close to the original form as possible and in as short a time as possible. Transmission and reception of this knowledge are the vital stages of good teaching. This guided acquisition of knowledge seems largely, predicated on a process of communication. We assume that listening to and reading about the topic are sufficient for our students to understand the matter. The belief in the efficacy of words in generating knowledge in learners is extraordinarily strong and seems so natural that we are reluctant to question it. In other words, we believe knowledge can be communicated to the learners through instruction i.e. lectures and notes and their ability to repeat the definition, formula or the process is proof enough of their mastery of the subject. Reproduction of what is learnt, however accurate obviously is no proof that the subject is understood. And even if they understand, knowing about a topic is no guarantee that the learner can use that knowledge.

It does not need much labour to convince anyone that all that can be achieved through this conventional perception of teaching is a rehearsed and replicative competence. There is little or no evidence that learners have grasped the concept they manage to repeat, much less apply it to any given situation. In fact, as long as the learning experience is teacher fronted, exam oriented and text dependent all science teaching would be reduced to teaching the history of science, teaching what the different scientists have achieved. Of greater importance is to bring about 
in us teachers, a change in perception, first of all to realise that knowledge is not really a product, much less that it can be pigeon holed into water tight subjects.

If educational efforts are, indeed, not successful, our implicit or explicit assumptions must be questioned. Two conclusions might be in order. One is that learning is a student led activity and that it is constructed rather than acquired through instruction. Unless the student is involved in the process of conceptualising and the operating there would be no real learning. Secondly that the restricted use of language for generating knowledge in the students does not take into account his/her total personality and all the learning competencies they are endowed with.

The concept now gaining wide acceptance is the theory of Multiple Intelligences. It is an important and holistic effort at breaking the mould of evaluating infelligence in narrow terms of linguistic and IQ tests, and including in the teaching-learning experience the other intelligences like the logical-mathematical, musical, spatial; kinaesthetic, interpersonal and intrapersonal intelligences. Why not establish different paths to learning using and supplementing the learning processes now confined to audio and visual senses only?

\section{A Paradigm Shift}

It would be valuable to apply Long's (1985) three level criteria to the present paradigm and consider whether knowledge transmission is necessary, sufficient and efficient. The most searching criterio, obviously is 'efficiency' which discerns whether the approach is a mere precondition for learning to take place (necessary and sufficient) or causes it to happen quickly and make it qualitatively better. It is intuitively clear that the construction model is not only necessary and sufficient to cause learning but also a really efficient way to understand and apply. This approach calls into play all the major factors listed below, that contribute to all round learning and a development of the whole person.

\section{Knowledge}

Terminology

Specific facts

Concepts and principles

Methods and procedures 


\section{Understanding}

Concepts and principles

Methods and procedures

Written materials, graphs, maps, and numerical data

Problem situations

\section{Application}

Factual Information

Concepts and Principles

Methods and Procedures

Problem Solving Skills

\section{Thinking Skills}

Critical Thinking

Scientific Thinking

\section{General Skilis}

Laboratory skills

Performance skills

Communication skills

Computation skills

Social skills

\section{Attitudes}

Social attitudes

Scientific attitudes

\section{Interests}

Personal interests

Educational and vocational interests 


\section{Adjustments}

\section{Social adjustments}

Emotional adjustments

Moreover, some recent research, empirical findings and sound theoretical constructs support the superiority and efficacy of the construction model.

Basically, the construction model fosters a dynamic, multi-dimensional awareness developing in the mind, and the ability to apply this awareness to their actual contexts. This is anytime superior to the not finite, articulated knowledge coming from outside. The approach is learner driven, teacher supervised, effort valuing and makes the participants develop a conceptual framework as well as problemsolving skills. It promotes student discussion and group activities, helping students experience science in varied, interesting, and enjoyable ways. As Yager points out, 'instead of being passive receptacles of knowledge, then, students collaborate with their teachers, and with each other, to see why their paths foward solutions to problems-and toward knowledge-seem promising to them' (1991). Owing to the challenge and motivation stemming from the authentic activity and relevant to the situation in which it will be applied learning becomes personal, interest engaging. The sense of ownership of the knowledge thus acquired, provides for long term storage and easy retrieval of what is learnt.

Jonassen lists the following features as crucial to an constructional design:

- Provide multiple representations of reality.

- Avoid oversimplification of instruction by representing the natural complexity of the world.

- Present authentic tasks - contextualize.

- Provide real-world, case-based learning environments, rather than predetermined instructional sequences.

- Foster reflective practice.

- Enable context- and content-dependent knowledge construction.

- Support collaborative construction of knowledge through social negotiation, not competition among learners for recognition. 
Again, in the Construction approach work undertaken is essentially a private affair and therefore becomes non-threatening/non-judgmental. Learner autonomy is promoted because in this approach, many of the learning decisions (e.g. about what to study, when to study, how to study, how long to study) are passed over to the person who ideally should control them - the learner. It supports personal explorations and even if in the process mistakes are committed there is no public loss of face. This form of non-public domain of learning may free learners to explore areas that they may not like to admit to not having understood earlier. The basics can be accessed endlessly until the persons who matter - the learners - are satisfied with their own performance or degree of understanding.

In this new paradigm, the teacher's role will no longer be to dispense "truth", but rather to help and guide the student in the conceptual organization of certain areas of experience. In her insightful book Dweck argues that learning is most effective when learners readily seek challenges and pour effort into them. It is the effort, the strategies, the ideas, what went into the work that ensures lasting and useful learning.

That calls for a paradigm shift. And the general lines of the shift has to be

$\begin{aligned} \text { from a product } & \text { to a process approach to learning } \\ \text { replicative } & \text { to an applicative mode } \\ \text { instructive } & \text { to constructive model } \\ \text { ability dependent } & \text { to strategy based }\end{aligned}$

learning by listening and reading to learning by doing

\section{Sample Learning by Doing Tasks}

1. The simplest one was to let the class, divided into groups of five attempt a task. They were given an egg, three balloons, enough twine and scotch tape. Using these and only these props they must design a method of safely landing the egg from the second floor to the ground below. They must work out an approach and defend it in scientific terms before the public display. All books with the required information were on display.

2. The second was a rather prolonged project under the guidance of competent persons in the protected industrial environment. The task was to prepare a display of tricolour fireworks on R-day. 
The group started by identifying and familiarizing themselves with the forms of energy involved in the project namely, sounds, light and heat. The colours they learnt are produced by heating metal salts and identified for the project at hand the three colours and the compounds needed as well as their wavelength.

\begin{tabular}{|l|l|l|c|}
\hline Color & \multicolumn{1}{|c|}{ Compound } & $\begin{array}{c}\text { Wavelength } \\
\text { (nm) }\end{array}$ \\
\hline Orange & $\begin{array}{l}\text { Calcium salts calcium chloride, } \\
\mathrm{CaCl}_{2}\end{array}$ & 668 \\
\hline Silver & $\begin{array}{l}\text { Burning aluminium, titanium, or } \\
\text { magnesium }\end{array}$ & \\
\hline Green & $\begin{array}{l}\text { Barium compounds }+\mathrm{chlorine} \\
\text { producer barium chloride, } \mathrm{BaCl}_{2}\end{array}$ & 589 \\
\hline
\end{tabular}

Understanding the process: Under competent guidance the group had identified colour, sound, heat, velocity, time lag as areas requiring deeper study and understanding. Inputs in the form of lectures, readings and discussions helped them get familiar with these. They next set about unraveling the carefully choreographed sequence of events beginning with the upward thrust, brilliant display of colours and a simultaneous marvellous explosion. The group went on to learn that colour and sound emanate from small clay or dough-like lumps or cubes comprising a blend of oxidising agent, reducing agent, colouring agent (metal salt), and binders are made by hand and carefully packed into cardboard compartments within the firework shell. It is these stars that produce both sound and light effects. The next challenge was to make them explode up in the sky. That led to their sequencing the two phases involved, one, the power needed to propel the firework into the air and the delayed power to the compartment containing the stars through a long fuse, even as the firework is hurtling skyward. A carefully calculated time delay fuse was introduced so that it reaches the compartment packed with the stars just when the firework is at the very apex of its upward flight.

A practical knowledge of the processes involved the precise combination of chemicals and the careful calibration result in a spectacular display of sound and a riot of colours. An actual exhibition of their handiwork under professional guidance brought their learning project to a glorious and colourful finale. No amount of lectures on oxidation and reductions, however well delivered would equal this single joyous experience of discovery and the attendant sense of ownership of the knowledge and proud display of their achievement for all to see. 


\section{References}

- Bergeron J.C. \& Herscovics N. (Eds.) Learning as Constructive Activity Proceedings of the 5th Annual Meeting of the North American Group of PME Montreal: PME-NA, 1983.

- Dweck, Carol S. Self-Theories: Their Role in Motivation, Personality, and Development, Psychology Press 2004.

- Active Learning http://mww.cti.ac.uk/publ/actlea.

- Jonassen (Jonasson, [On-line]). 